Journal of Social Sciences 6 (3): 439-442, 2010

ISSN 1549-3652

(C) 2010 Science Publications

\title{
Thai Local Entertainment of Local Community in Mae-Klong River Basin: Knowledge Management for Inheriting Local Culture of Primary School
}

\author{
Saksin Chongdarakul, Songkun Chankajon and Ratchanon Supapongpichait \\ The Research Institute of North Eastern Arts and Culture, \\ Mahasarakham University, Maha Sarakham, 44000, Thailand
}

\begin{abstract}
Problem statement: Local entertainment was an activity providing the pleasure, joyfulness and recreation. The objectives of this research were to study: (1) the historical background of cultural factor and body of knowledge in local entertainment, (2) the usefulness in inheriting and problems in Thai Local Entertainment and (3) the knowledge management model of Thai Local Entertainment in Primary School for carrying on the local culture. Approach: The research area: Middle Region Provinces of Thailand including: Kanchanaburi, Rachburi and Samutsongkram Provinces. The informants were selected by Purposive Sampling, 110 persons. The instrument using for collecting data consisted of the Interview Form, the Observation Form, the Focus Group Discussion and Participatory Workshop. Qualitative data were analyzed and presented in descriptive analysis. Results: The findings; (1) the historical background and body of knowledge in Thai Local Entertainment in the research area with ethnic groups: Ka-rieng, Mon, China, Lao, Mienma, Lawa, Ka-mu and Thai. Each group had different local entertainment owing to its culture which wasn't clear that it started during which reign. But, most of entertainments was related to daily life including: the occupation, celebration, principle if farming, annual festival, tradition relating to life from birth to death and belief in ghost and god. For entertainment, the public space would be used such as the temple, the courtyard of house and the house etc. The aim of entertainment was for recreation after work and entertainment according to one's belief. As a result, the social hierarchy and unity occurred, (2) Thai Local Entertainment was useful in many dimensions: (1) to understand the surrounded things, (2) to transfer the wisdom, enhance thought, joyfulness, pleasure by using wittiness, (3) to inherit the knowledge among ages, (4) to be a study and sharing of learning and (5) to carry on the social value, (6) the knowledge management model for inheriting Thai Local Entertainment, according to the studies found that there were following issues: (1) the creation of vision, mission, goal, indicator and concept. The local entertainment provided major material, (2) the construction and search for knowledge, (3) the management of knowledge to be systematic, (4) the collection of knowledge, (5) the access of knowledge and expansion of knowledge, significance, awareness, correction, improvement the activities, (6) the sharing of learning from entertainment and (7) the system enhancing and carrying on the learning technique of local entertainment continuously by developing the innovation media in different social units. Conclusion/Recommendations: This research could be a guideline for conserving and being the knowledge management of local entertainment which was valuable culture in order to be exist with Thai Society further.
\end{abstract}

Key words: Thai local, entertainment, community, Mae-Klong River, knowledge management, local culture

\section{INTRODUCTION}

Knowledge Management played a major role in inheriting and deciphering the experience and thinking technique for carrying on Thai culture, wisdom and entertainment as well as developing the youth's quality of life. According to the approach and importance as the above, it could be viewed that the education was a key strategy in preparing the new youngsters to be able to inherit the social culture. Therefore, school played an important role in those duties. The management of Primary School Curriculum was the educational management relevant to locality focusing on being Thais, good citizen of the country, livelihood,

Corresponding Author: Saksin Chongdarakul, The Research Institute of North Eastern Arts and Culture,

Mahasarakham University, Maha Sarakham, 44000 Thailand Tel: +66-43-742827 
occupation and studying in higher level. The Primary Schools organized the material of curriculum in section relating to condition of problems in community and society, local wisdom, desirable characteristics for being good member of family, social community and country based on unity in policy, variety in practice, as a core curriculum with flexible structured curriculum. The objectives were specified as 12 years overall learning standard, learning substance, each group of learning standard, class level learning standard, 3 years each class level. Only necessary sections were managed for developing the quality of life, being Thais, being national god citizen, livelihood and occupation, as well as furthering the education according to one's potentiality.

According to the background and significance of problems as the above, the researcher was interested in Thai Local Entertainment in Ma-Klong River Basin Area with identity significance of each locality, it was also closely related to humans' livelihood and significant surroundings of society as recreational activities during leisure time which was to spend one's time in variety of usefulness. Local Entertainment was a shrewd plan for enhancing unity and generosity with each other. But, the inheritance of major work units as well as Primary Schools situated in locality, didn't give an importance to it. As a result, the inheritance of entertainment was missing in some parts. So, it wasn't link together because it was a lack of knowledge management process which would make the related organization working units could implement in searching, selecting, organizing the extended system, transferring information technology, or using skill and experience for constructing necessary knowledge and wisdom sources from work practice in order to achieve goal, didn't accomplish as it should be. Furthermore, the problems in instructional management for carrying on the culture of schools or educational institutes, lacking of knowledge, approach, model, comprehension in systematic implementation. Therefore, if there was a study of knowledge management in Thai Local Entertainment of local community in Ma-Klong River Basin Area, there would be systematic inheritance of local culture in Primary Schools based on appropriate steps. So, the researcher was interested in studying and developing the Thai Local Entertainment of local community in Ma-Klong River Basin Area using knowledge management process for inheriting the culture of Primary Schools as learning source and creating the value of revitalizing, conserving and maintaining the local wisdom in order to disseminate knowledge network and transfer to Primary Schools for developing Thai Society into learning society based on the Educational Service Area situated in Ma-Klong Basin River Area: Kanchanaburi, Rachaburi and Samutsongkram Provinces which would move the knowledge management for increasing the efficiency of practitioner community organization in cultural aspect under the economic and social environmental condition of knowledge-based in development further.

\section{MATERIALS AND METHODS}

The studied area included 3 provinces in Ma-Klong River Basin: Kanchanaburi, Rachburi and Samutsongkram Provinces. Qualitative Research was administered in this research. Data were collected from the samples as Purposive Sampling including: 10 experts, 50 key informants, 50 general villagers, total of 110 persons. The instrument using for collecting data consisted of the Structured Interview, the Un-structured Interview, Participatory Observation, Non-participatory Observation, Focus Group Discussion and Participatory Workshop. Data were investigated to be relevant to the specified problem issues and presented in descriptive analysis.

\section{RESULTS}

The research findings were as follows:

- The context of area in Kanchanaburi, Rachburi and Samutsongkram Provinces, according to different historical backgrounds of the ethnic people living in the area for alone period of time. There was a creation of knowledge in entertainment in locality as a knowledge system with continuous development through dimension of relationship between human beings and nature as well as culture with identity in each locality. But, it was closely related to livelihood and environment of people living in. The body of knowledge in Thai Local Entertainment in Ma-Klong River Basin was an implicit in human beings both of children and adults. So, it was one dimension reflecting the identity of community regarding to Thought, Belief, Social Values and Intellectual Value Development of those localities

- Thai Local Entertainment was useful in understanding the surroundings. It was advantage in various dimensions including the usefulness and good points in transferring the wisdom, encouraging for thought, pleasure, joyfulness and wittiness. For management of knowledge transfer, it was performed by demining in vision, mission, search for sharing of learning, developing 
descendants of new generation, accessing in origin of intellectual cultivation. The related work units should enhance the knowledge management as well as use the local context as clearer learningbased, learning by real practicing, searching for knowledge, creating the meaning in what was learned, as well as sharing one's experience, value, belief and process, in order to be Tacit Knowledge hidden in each kind of entertainment and Explicit Knowledge disseminating in various types of media, the youngsters used to be useful for themselves and their society

- The model of knowledge management for inheriting Thai Local Entertainment in Ma-Klong River Basin Area of Primary Schools, needed to include: (1) the vision, mission, goal, indicator, concept, content, material of entertainment in local entertainment whether it was or where was it, (2) there was development and search for knowledge, 3 ) the knowledge management as systematic, (4) the collection of knowledge, (5) the access in knowledge and extension of knowledge by giving an importance, being aware of, correcting and improving the activities continuously, (6) the sharing of knowledge with systematic implementation, supplementary in various activities, organization of instructional management including analytical thinking in quality decision making, educational management both of inside and outside schools based on the context of area and (7) the system for enhancing and inheriting the learning technique of entertainment by developing the activities, innovation media of school and community regularly by knowledge management and enhancement for related factors which would be useful for oneself and society so that the local entertainment wouldn't be disappeared from community

\section{DISCUSSION}

According to research findings, the discussions would be as follows:

- Thai Local Entertainment was a media closing to community very much especially the context in inheriting for learning by people living in the same context by the observation technique, trying out the practice, as well as transferring the good value. Besides, it was also the inculcating for value in the love between friends, respect for elders, awareness in ethnic and race, in order to enhance the unity in people group. It was supported by the finings of factors in inheriting for wisdom of local art and culture, support by the research findings of Neungchaloem (2003) that the learning both of Social Science and Science from way of life, culture and tradition would lead to the thinking technique and searching for guidelines in developing body of knowledge by "Observation Skill"

- For problems of Thai Local Entertainment in MaKlong River Basin, most of them caused by economic and social situations. As a result, there was a shortage of the state in lacking of: the player or performer, inherited persons in traditional body of knowledge from the real model origin, the male and female song leaders for entertaining, ceremony leader, serious inheriting, carry on from generation to generation. Consequently, there were entertainments sonly in some locality, without extending to the wide area. For entertainment, it was based on rule, regulation. It was supported by Chantavanich et al. (2001) approach in proposing the observation technique in social phenomenon which would lead to cultural problems including: the Acts, Activities, Meanings, Relationship, Participation in activity of community, Setting of society. It would be viewed that according to the above effects, it would be caused by adaptation of Thai Culture

- For the study in problems of Thai Local Entertainment, found that the recreation, value of a technique period using for opposing the superimpose or showing reaction to the decreasing in traditional cultural value: the use of local knowledge as a tool in withstanding the dominated trend. The local knowledge or villager knowledge was a Social Memory in value aspect. It was like a Cultural Space or Social Stage facilitating many people groups in society to create, learn, interpret, share and blend with various kinds of knowledge for bargaining, fighting, an challenging with the overshadow. Moreover, the villager knowledge was also being able to limit the power of globalization trend in changing the culture into the items. It was supported by the approach that the social change consisted of process with hierarchy from one step to another step as the higher level of development of progress than the former one. There was a social change from simple society to the more complex one which was caused by the more modern communication

- For usefulness, inheritance and problems in Thai Local Entertainment in Ma-Klong River Basin 
Area, it would be different based on the kind of ethnic and race, religious belief. It was useful and precious from the show as carrying on valuable villagers' lifestyle. It was supported by Wattanachai (2004) statement that the culture refers to a type of civilization especially in the part relating to different beliefs, art, customs and traditions. Then, it is invented as valuable product using for living. It was supported by Samudavanija (1996) statement on New Paradigm of organization in managing the education in present and future world that the process should be more emphasized than the structure. New educational system had to be various kinds, not be rigid, be based on collaboration from every sector as multilateral system for managing the holistic education with 2 aspects of common goal: the creation for citizen competency and development of facilitating state. For major components of knowledge management process, it consisted of 6 phases: the search for knowledge, development of knowledge, sharing of knowledge, storage of knowledge, transfer of knowledge and application of knowledge

\section{CONCLUSION}

Local entertainment was an activity for pleasure, joyfulness and recreation aligned with exercise. It was a useful for physical, emotional, social and mental development of every human beings' gender and age. It reflected the local identity, villagers' livelihood in society or locality. It was an inherited culture in lifestyle of villagers from the past to the present. So, it should be preserved in order to be exist in Thai Locality and Society.

\section{REFERENCES}

Chantavanich, S., S. Nittayananta, P. Ratanaolan-Mix, P. Ruenkaew and A. Khemkrut, 2001. The migration of Thai women to Germany: Causes, living conditions and impacts for Thailand and Germany. Asian Research Center for Migration.

Neungchaloem, P., 2003. Design of backward learning. J. Hum. Soc. Sci., 26: 17-24.

Samudavanija, C.A., 1996. Political future of Thailand. 2nd Edn., The Office of Policy Study, Bangkok, ISBN: 974-8196-21-6, pp: 78.

Wattanachai, K., 2004. Thai society-learning society. National Public Health Association. 